\title{
The realization of automatically adjusting the adaptive PID parameters based on the theory of fuzzy mathematics
}

\author{
DeSheng Zhong
}

Guidaojiaotong Polytechnic Institute, Shenyang 110023, China

Keywords: Brushless DC Motor; Fuzzy PLD; adaptive control; parameter self-tuning.

\begin{abstract}
Design of the main controller using fuzzy logic theory on the basis of the traditional PID control, Using the fuzzy mathematics theory, the use of fuzzy sets to represent the regular condition, and the fuzzy control rules and the relevant information in the control system in the knowledge base as a knowledge, According to the actual response of control object, control system using fuzzy reasoning, to complete the optimal adjustment of PID parameters.
\end{abstract}

\section{Introduction}

Brushless DC Motor(BLDCM) has excellent speed regulating performance, and overcame many problems that brought by the Brush DC Motor(BDCM) mechanical commutator, won a wide application in all fields. However, the time-varying, nonlinear and strong coupling features of Brushless DC Motor leads to the traditional PID control is difficult to meet the performance requirements of control system[1]. Control quality of traditional PID controller depends on the parameter setting, system under various running status always use the same set of parameters obviously lead to bad operation.

\section{The structure of BLDCM control system}

The hardware part of this control system is mainly composed of storage battery and inverter circuit, switch tube driving and protecting circuit, power circuit, system control unit and its peripheral circuit, current and voltage signal detection circuit, etc. Using three-phase bridge inverter circuit as a power main circuit, power supply using storage battery; Use of Motorola Company DSP56F803 control unit; Armature winding Y, 3 phase 8 pole; Choose Fuji 1MBH60-100 IGBT switch tube, Drive protection module of IGBT using EXB841. Battery, power inverter circuit and the circuit of BLDCM connection as shown in figure 1. Y type armature winding connection, use of voltage type three-phase full bridge inverter circuit as the power inverter circuit.

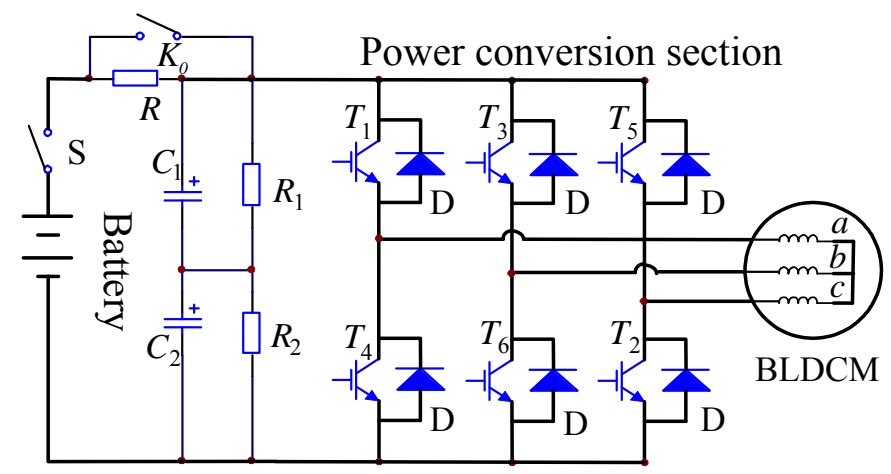

Fig. 1 Circuit diagram of motor and battery power inverter circuit

The control of system using double closed-loop, Speed controller designed by using fuzzy adaptive PID method instead of the traditional speed regulator[2]. Control system block diagram is shown in figure 2 . 


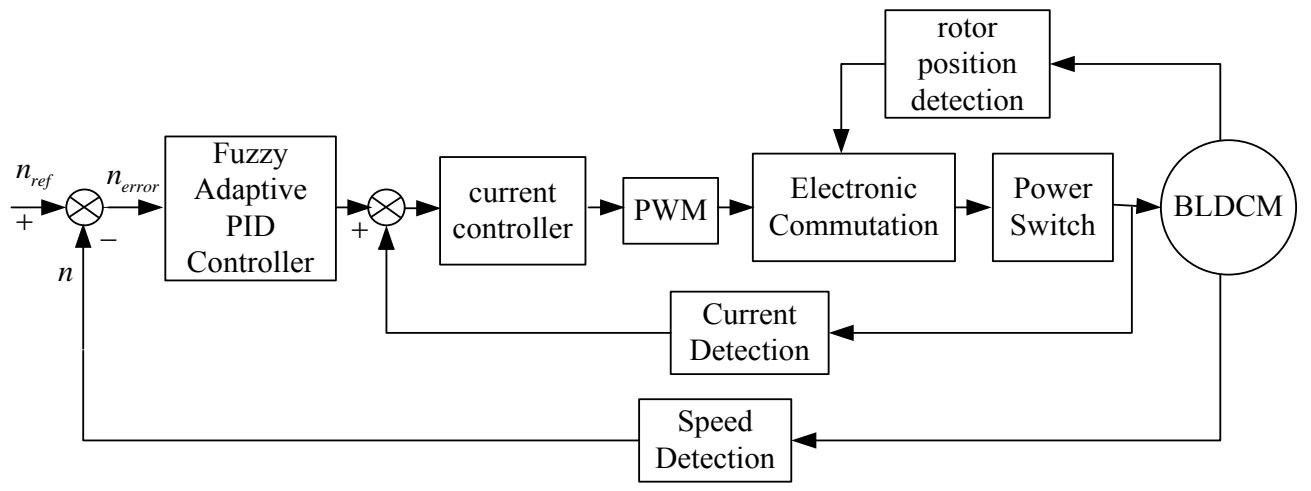

Fig. 2 BLDCM Control system block diagram

\section{Design of the fuzzy adaptive PID controller}

The motor's actual speed of the he fuzzy adaptive PID controller is $n$, the temperature deviation of a given value $n_{\text {ref }}$ is $n_{\text {error }}$, the change of the deviation is $E C=\Delta E / T_{s}$, As the input language variable. Output language variables are three PID parameters are revised, three variables form a two-dimensional fuzzy controller. Using the rules of fuzzy control to modify the PID parameters online, meet the needs of different time and the requirement of parameter self-tuning. Meet the $E$ and $E C$ of parameter self-tuning requirements at different times. The controller structure is shown in figure 3 .

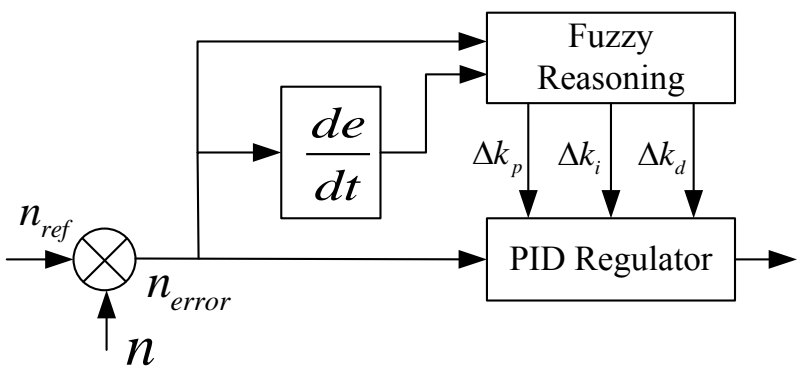

Fig. 3 Fuzzy adaptive PID controller

Determine the error of the controlled system $E=\left[-X_{E}, X_{E}\right]$, change of error $E C=\left[-X_{E C}, X_{E C}\right]$, Control

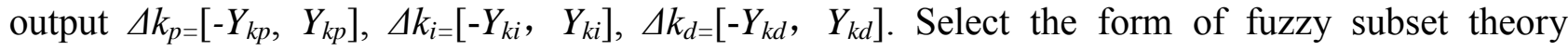
domain $\{-m,-m+1, \ldots, 0, \ldots, m-1, m\},\{-n,-n+1, \ldots, 0, \ldots, n-1, n\},\{-i,-i+1, \ldots, 0, \ldots$, $i-1, i\},\{-j,-j+1, \ldots, 0, \ldots, j-1, j\}$ and $\{-k,-k+1, \ldots, 0, \ldots, k-1, k\}$. Select the fuzzy subset of language variable of $\mathrm{IO}\{\mathrm{NB}, N M, N S, Z O, P S, P M, P B\}$. Membership functions overlap symmetric distribution of the triangle membership function, fuzzy sets the membership degree of each assignment can be obtained.

The principle of fuzzy self-tuning PID parameters: find the relationship of three parameters of PID and fuzzy between the $E$ and $E C$, Real-time detection $E$ and $E C$ at the time of system running, modify the three parameters on-line according to the principle of fuzzy control. In order to satisfy different $E$ and $E C$ cases for different requirements of the control parameters, make the controlled object has a good dynamic and static performance. From the dynamic and static performance analysis of the controlled $k_{p}, k_{i}$ and $k_{d}$ : The role of Proportional coefficient $k_{P}$ is to accelerate the response speed of system, improve the accuracy of the system. The value of $k_{P}$ is greater, the response speed of system is faster, regulation has the higher precision, but are prone to overshoot, $k_{P}$ 's value decreases, and can reduce the accuracy, make response speed slow; The role of Integral coefficient $k_{i}$ is to eliminate the steady-state error of the system, if the value of $k_{i}$ is bigger, can make the response process produces large overshoot. On the other hand, the value of $k_{i}$ is too small, 
will make the system difficult to eliminate static error, affect the system's accuracy; The effect of differential coefficient $k_{d}$ is inhibit the change of the deviation in the process of response. But the value of $k_{d}$ is oversize will extend to adjust time and reduce the anti-interference ability of the system.

Consider the role of three control parameters at the different time, and the relationship between each other, summarizes the operation experience of $\Delta k_{p}, \Delta k_{i}$ and $\Delta k_{d}$, calculated the fuzzy rules table is as follows:

Table 1 Fuzzy control rules of $\Delta k_{p}$

\begin{tabular}{|c|c|c|c|c|c|c|c|}
\hline $\begin{array}{l}\text { EQ } \\
E\end{array}$ & NB & NM & NS & ZO & PS & PM & PB \\
\hline NB & PB & PB & PM & PM & PS & ZO & ZO \\
\hline NM & PB & PB & PM & PS & PS & ZO & NS \\
\hline NS & PM & PM & PM & PS & ZO & NS & NS \\
\hline ZO & PM & PM & PS & ZO & NS & N & N \\
& & & & & & M & M \\
\hline PS & PS & PS & ZO & NS & NS & N & N \\
& & & & & & M & M \\
\hline PM & PS & ZO & NS & N & N & N & NB \\
& & & & M & M & M & \\
\hline PB & ZO & ZO & N & N & N & NB & NB \\
& & & M & M & M & & \\
\hline
\end{tabular}

Table 2 Fuzzy control rules of $\Delta k_{i}$

\begin{tabular}{|c|c|c|c|c|c|c|c|}
\hline$E C$ & NB & NM & NS & ZO & PS & PM & PB \\
\hline NB & NB & NB & NM & NM & NS & ZO & ZO \\
\hline NM & NB & PB & NM & NS & NS & ZO & ZO \\
\hline NS & NB & NM & NS & NS & ZO & PS & PS \\
\hline ZO & NM & NM & NS & ZO & PS & PM & PM \\
\hline PS & NM & NS & ZO & PS & PS & PM & PB \\
\hline PM & ZO & ZO & PS & PS & PM & PB & PB \\
\hline PB & ZO & ZO & PS & PM & PM & PB & PB \\
\hline
\end{tabular}

Table 3 Fuzzy control rules of $\Delta k_{d}$

\begin{tabular}{|c|c|c|c|c|c|c|c|}
\hline NB & PS & NS & NB & NB & NB & $\begin{array}{c}\text { N } \\
\text { M }\end{array}$ & PS \\
\hline NM & PS & NS & NB & $\begin{array}{c}\text { N } \\
\text { M }\end{array}$ & $\begin{array}{c}\text { N } \\
\text { M }\end{array}$ & NS & ZO \\
\hline NS & ZO & NS & $\begin{array}{c}\text { N } \\
\text { N }\end{array}$ & NS & NS & ZO \\
\hline ZO & ZO & NS & NS & NS & NS & NS & ZO \\
\hline PS & ZO & ZO & ZO & ZO & ZO & ZO & ZO \\
\hline PM & PB & NS & PS & PS & PS & PS & PB \\
\hline PB & PB & PM & PM & PM & PS & PS & PB \\
\hline
\end{tabular}


USES Mamdani fuzzy logic reasoning, gravity method to solve the fuzzy algorithm, can find out $\left\{E i, E C_{j}\right\}$ the precise output, plug in the following equation:

$$
k_{p}=k_{p 0}+\left\{E_{i}, E C_{j}\right\}_{p}, \quad k_{i}=k_{i 0}+\left\{E_{i}, E C_{j}\right\}_{i}, \quad k_{d}=k_{d 0}+\left\{E_{i}, E C_{j}\right\}_{d}
$$

$k_{p 0} 、 k_{i 0}$ and $k_{d 0}$ are the initial value of the three parameters.

For all combinations of input, calculation control output, compose the fuzzy control table. Real-time detection during the operation of $E$ and EC, all parameters in the control table lookup the revised accordingly, completed three parameters self-tuning PID online.

\section{Experimental result}

The response curves of speed when the PID control as shown in figure 4. Curve 1 is the response curves of speed when the traditional PID control, the curve 2 is the response curves of speed when fuzzy self-tuning PID control. Through the contrast can be found that the fuzzy self-tuning PID control, fast response, small overshoot, speed fluctuation is small, it has good dynamic and static characteristics.

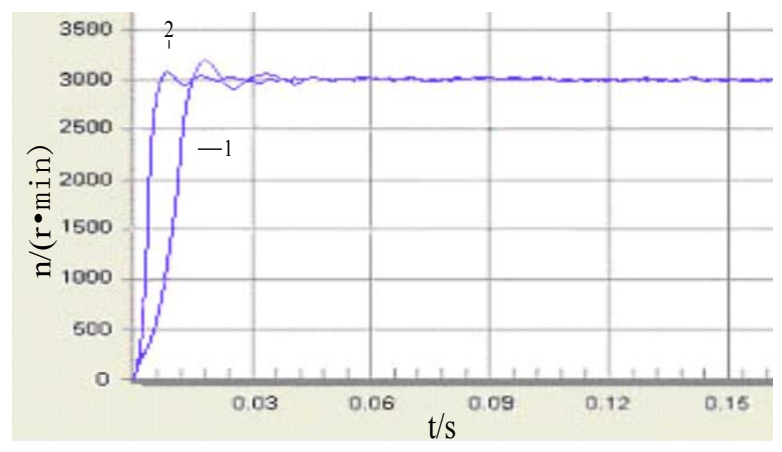

Fig. 4 Response curves of speed when the PID control

When the motor running, sudden increase load under the condition of the speed of response curve is shown in figure 5.Respectively by traditional PID and fuzzy self-tuning PID control of brushless dc motor speed curve. Found that the fuzzy self-tuning PID control system has better dynamic performance than traditional PID control.

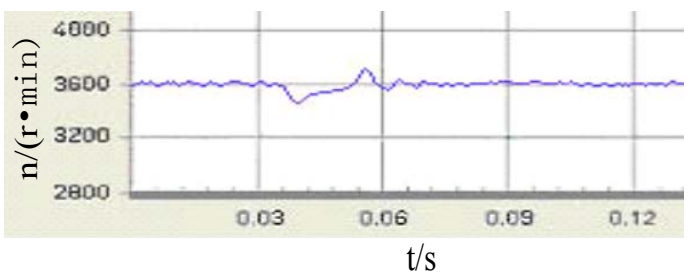

(a)The raditional HD regulation

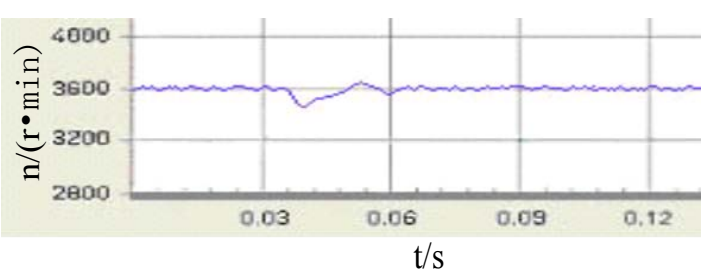

(b)The fizzy slf-tuning PID regulation

Fig. 5 Response curve of the speed when sudden increase of the load

\section{Summary}

This paper design the BLDCM double closed loop control system that based on the DSP56F803, speed loop adopts fuzzy self-tuning PID control is realized for BLDCM speed control. By the experiment of add load to the motor during starting and running processes, it is concluded that the control method is superior to traditional PID control. The BLDCM control system has good dynamic and static performance, strong robustness, has the value of popularization and application. 


\section{References}

[1] Zhu Ying, Zhu Jun. Several kinds of PID control and simulation comparison, J. Industrial Control Computer 23(2010) 23 53-54.

[2] Zeng Guie, Qiu Li, Zhu Xuefeng. The simulation and experiment on the parameter-tuning methods of PID controllers, J. Automation in Petro-Chemical Industry 20 (2005) 20-23. 